\title{
Empathy, Self-Efficacy and Nursing Performance of Nurses at Care Hospitals
}

\author{
Song-hee Park ${ }^{1}$ and Bong-sil Choi ${ }^{2 *}$ \\ Department of Nursing, Nambu University, 23 Chumdan Jungang-ro, \\ Gwangsan-gu, Gwangju, Korea \\ 'psh.6088@hanmail.net, ${ }^{2 *}$ choibs@nambu.ac.kr
}

\begin{abstract}
The purpose of this study is to investigate the relationship between empathy, self-efficacy, and nursing performance of nursing hospital nurses. The results of the study are as follows. When compiling all the research above, the higher the empathy of the nurse of the nursing hospital and higher the self-efficacy reported higher nursing performance. Empathy was higher according to marital status and satisfaction with nursing. Self-efficacy was also reported to be higher when the satisfaction of nursing was high. The nursing performance showed differences according to marital status and working style.
\end{abstract}

Keywords: Nurses, Care hospitals, Empathy, Self-efficacy, Nursing performance

\section{Introduction}

\subsection{Necessity of study}

To be specific, care hospital nurses involve themselves in direct and indirect nursing care to treat diseases of elderly patients, carry out specialized nursing care activities, provide patients with specific care services by organizing teams for rehabilitation training and adjustment training, and help patients with activities of daily living [1]. In addition, their nursing services cover training, management, and supervision of nurse's aides and caregivers who are non-medical personnel, psychological care of dying patients, safety management for patients, part of doctor's area of practice, and consultations with patients' guardians [2].

However, nurses spend more time performing mechanical tasks than directly treating patients, and thus, patients tend to have a sense of distance from nurses who do not show empathy for their conditions [3]. Nurses' great empathy for elderly patients is perceived as a positive attitude towards them [4]. Therefore, empathy is deemed to be a major factor in developing a therapeutic relationship and also influences even therapeutic effects. In that sense, it is necessary to stimulate nurses' empathy. Nurses' greater self-efficacy can motivate patients to do individual activities and accept changes in nursing care settings [5]. In addition, nurses' self-efficacy becomes an important factor influencing job stress and job satisfaction, thus having a positive effect even on nursing performance. Further, it is related to providing elderly patients with high-quality nursing care [6][7]. Therefore, this study is aimed at verifying the relevance between care hospital nurses' empathy, self-efficacy, and nursing performance.

Article History:

Received (December 2, 2019), Review Result (January 19, 2020), Accepted (February 22, 2020) 


\subsection{Objectives of the Study}

To identify the degree of subjects' empathy, self-efficacy, and nursing performance.

To identify differences in empathy, self-efficacy, and nursing performance depending on subjects' general characteristics.

To identify the correlation between subjects' empathy, self-efficacy, and nursing performance.

\section{Study method}

\subsection{Study design}

This study was designed as correlational research to analyze the correlation between care hospital nurses' empathy, self-efficacy, and nursing performance.

\subsection{Subjects}

A total of 152 nurses from seven care hospitals were selected as subjects of this study, and 150 , except two who responded insincerely or inadequately, were selected as final subjects.

\subsection{Study tools}

\subsubsection{Empathy}

For empathy assay, Jeon [8]'s empathy tool was used. This tool consisted of a total of 30 questions: 15 questions each for cognitive empathy and emotional empathy. Cognitive empathy involves taking a viewpoint and imagining, and emotional empathy is related to empathic concern and personal pain. A 5-point Likert scale was used, ranging from 1 ('Strongly Disagree') to 5 ('Strongly Agree'), which means the higher the score, the greater the empathy. When it comes to the reliability of this tool, Cronbach's $\alpha$ was .83 for the study by Jeon's and .85 for this study [8].

\subsubsection{Self-efficacy}

For self-efficacy, Jung's tool targeted at nurses was used [9]. This tool consisted of a total of 17 questions, based on the 5-point Likert scale. The higher the score, the greater the selfefficacy on a scale of 1 ('Never') to 5 ('Always'). When it comes to the reliability of this tool, Cronbach's $\alpha$ was .94 for the study by Jung and .94 for this study [9].

\subsubsection{Nursing performance}

The tool developed by Ko, Lee \& Lim [10] targeting nurses was used to assess nursing performance. This tool consisted of a total of 17 questions: 7 questions for nursing task performance ability, 4 questions for nursing task performance attitude, 3 questions for nursing task level improvement, and 3 questions for nursing care process application. A 5-point Likert scale was used; the higher the score, the greater the nursing performance on a scale of 1 ('Strongly Disagree') to 5 ('Strongly Agree'). When it comes to the reliability of this tool, Cronbach's $\alpha$ was .92 for the study by Ko, Lee \& Lim and .93 for this study [10]. 


\subsection{Data collection \& analysis}

For data collection, seven care hospitals were randomly selected in J-do Province. Questionnaires were distributed directly to the subjects and their responses were collected. The respondents were allowed to fill in the questionnaires in a separate space before or after work to ensure their confidentiality, etc.

Data analysis was implemented using SPSS/WIN 24.0 program.

- The mean and standard deviation of the degree of empathy, self-efficacy, and nursing performance were determined.

- To verify differences in variables depending on general characteristics, t-test, one-way, and ANOVA were used, and a Post-Hoc test was implemented using Scheffe's test.

The relationship between empathy, self-efficacy, and nursing performance was analyzed using Pearson's correlation coefficient.

\section{Results}

\subsection{Degree of empathy, self-efficacy, and nursing performance}

The scores of empathy, self-efficacy, and nursing performance were $3.62 \pm 0.31$ points, $3.69 \pm 0.46$ points, and $3.76 \pm 0.39$ points, respectively, out of 5 points [Table 1].

Table 1. Degree of empathy, self-efficacy, and nursing

\begin{tabular}{|c|c|c|c|}
\hline Variables & $\mathrm{M} \pm \mathrm{SD}$ & Min-Max & Range \\
\hline Empathy & $3.62 \pm 0.31$ & $2.63-4.57$ & $1-5$ \\
\hline Self-efficacy & $3.69 \pm 0.46$ & $2.53-5.00$ & $1-5$ \\
\hline Nursing performance & $3.76 \pm 0.39$ & $2.94-5.00$ & $1-5$ \\
\hline
\end{tabular}

\subsection{Differences in empathy, self-efficacy, and nursing performance depending on general characteristics}

Empathy showed a statistically significant difference depending on marital status $(\mathrm{t}=-2.55$, $\mathrm{p}=.012$ ), and the results of the post-hoc test revealed that empathy was greater among married nurses than single nurses. Empathy also showed a statistically significant difference depending on satisfaction with nursing as a job $(\mathrm{F}=5.55, \mathrm{p}=.001)$; 'Very Satisfied' was more frequently selected than 'Satisfied', 'Mediocre', and 'Dissatisfied'. Self-efficacy showed a statistically significant difference depending on satisfaction with nursing as a job ( $\mathrm{F}=4.94$, $\mathrm{p}=.003$ ), and the results of the Post-Hoc test revealed that in terms of self-efficacy, 'Very Satisfied', 'Satisfied', and 'Mediocre' were more frequently selected than 'Dissatisfied'. In terms of marital status $(\mathrm{t}=-2.34, \mathrm{p}=.021)$, nursing performance was statistically higher among married nurses than single nurses. In terms of work pattern $(\mathrm{t}=.25 \mathrm{p}=.006)$, nursing performance was revealed to be statistically significantly higher in fixed-shift nurses than in 3-shift ones [Table 2]

\subsection{Correlation between empathy, self-efficacy, and nursing performance}

The nursing performance showed a statistically significantly positive correlation with empathy $(\mathrm{r}=.34, \mathrm{p}<.001)$ and self-efficacy $(\mathrm{r}=.62, \mathrm{p}<.001)$. There was also a positive correlation $(\mathrm{r}=.39, \mathrm{p}<.001)$ between empathy and self-efficacy, which was statistically significant [Table 3]. 
Table 2. Differences in empathy, self-efficacy, and nursing performance depending on general characteristics

\begin{tabular}{|c|c|c|c|c|c|c|c|}
\hline \multirow{3}{*}{$\begin{array}{l}\text { Characte } \\
\text { ristics }\end{array}$} & \multirow{3}{*}{ Categories } & \multicolumn{2}{|c|}{ Empathy } & \multicolumn{2}{|c|}{ Self-efficacy } & \multicolumn{2}{|c|}{ Nursing-performance } \\
\hline & & \multirow{2}{*}{$\mathrm{M} \pm \mathrm{SD}$} & $\mathrm{t} / \mathrm{F}(p)$ & \multirow{2}{*}{$\mathrm{M} \pm \mathrm{SD}$} & $\mathrm{t} / \mathrm{F}(p)$ & \multirow{2}{*}{$\mathrm{M} \pm \mathrm{SD}$} & $\mathrm{t} / \mathrm{F}(p)$ \\
\hline & & & Scheffe' & & Scheffe' & & Scheffe' \\
\hline \multirow{5}{*}{$\begin{array}{l}\text { Age } \\
(\mathrm{yr})\end{array}$} & $20-29$ & $3.56 \pm 0.39$ & \multirow{5}{*}{$\begin{array}{c}1.16 \\
(.332)\end{array}$} & $3.61 \pm 0.49$ & \multirow{5}{*}{$\begin{array}{c}.766 \\
(.549)\end{array}$} & $3.57 \pm .36$ & \multirow{5}{*}{$\begin{array}{c}2.18 \\
(.074)\end{array}$} \\
\hline & $30-39$ & $3.55 \pm 0.38$ & & $3.62 \pm 0.44$ & & $3.74 \pm .43$ & \\
\hline & $40-49$ & $3.69 \pm 0.27$ & & $3.71 \pm 0.44$ & & $3.85 \pm .37$ & \\
\hline & $50-59$ & $3.64 \pm 0.26$ & & $3.77 \pm 0.48$ & & $3.80 \pm .38$ & \\
\hline & $\geq 60$ & $3.66 \pm 0.28$ & & $3.69 \pm 0.31$ & & $3.77 \pm .27$ & \\
\hline \multirow{2}{*}{ Gender } & $\mathrm{M}$ & $3.41 \pm 0.54$ & \multirow{2}{*}{$\begin{array}{l}-1.41 \\
(.184)\end{array}$} & $3.76 \pm 0.35$ & \multirow{2}{*}{$\begin{array}{l}.395 \\
(.694)\end{array}$} & $3.62 \pm .37$ & \multirow{2}{*}{$\begin{array}{l}-1.62 \\
(.109)\end{array}$} \\
\hline & $\mathrm{F}$ & $3.64 \pm 0.28$ & & $3.70 \pm 0.45$ & & $3.81 \pm .38$ & \\
\hline \multirow{2}{*}{$\begin{array}{c}\text { Marital } \\
\text { status }\end{array}$} & Single & $3.51 \pm 0.37$ & \multirow{2}{*}{$\begin{array}{l}-2.55 \\
(.012)\end{array}$} & $3.61 \pm 0.38$ & \multirow{2}{*}{$\begin{array}{l}-1.39 \\
(.166)\end{array}$} & $3.64 \pm .42$ & \multirow{2}{*}{$\begin{array}{l}-2.34 \\
(.021)\end{array}$} \\
\hline & Married & $3.66 \pm 0.28$ & & $3.73 \pm 0.48$ & & $3.80 \pm .36$ & \\
\hline \multirow{3}{*}{$\begin{array}{l}\text { Educati- } \\
\text { on }\end{array}$} & College & $3.60 \pm 0.28$ & \multirow{2}{*}{$\begin{array}{c}1.99 \\
(.140) \\
\end{array}$} & $3.64 \pm 0.49$ & \multirow{2}{*}{$\begin{array}{c}2.45 \\
(.090) \\
\end{array}$} & $3.74 \pm .42$ & \multirow{2}{*}{$\begin{array}{c}.891 \\
(.412)\end{array}$} \\
\hline & University & $3.64 \pm 0.37$ & & $3.82 \pm 0.37$ & & $3.80 \pm .31$ & \\
\hline & $\geq$ Master & $4.03 \pm 0.47$ & & $3.76 \pm 0.33$ & & $4.03 \pm .04$ & \\
\hline \multirow{5}{*}{$\begin{array}{c}\text { Total } \\
\text { clinical } \\
\text { career } \\
(\mathrm{yr})\end{array}$} & $1->5$ & $3.62 \pm 0.41$ & \multirow{5}{*}{$\begin{array}{c}.05 \\
(.996)\end{array}$} & $3.67 \pm 0.47$ & \multirow{5}{*}{$\begin{array}{c}.78 \\
(.542)\end{array}$} & $3.63 \pm .38$ & \multirow{5}{*}{$\begin{array}{c}2.32 \\
(.060)\end{array}$} \\
\hline & $5->10$ & $3.63 \pm 0.32$ & & $3.74 \pm 0.47$ & & $3.80 \pm .40$ & \\
\hline & $10->15$ & $3.61 \pm 0.28$ & & $3.71 \pm 0.43$ & & $3.88 \pm .38$ & \\
\hline & $15->20$ & $3.61 \pm 0.24$ & & $3.58 \pm 0.52$ & & $3.72 \pm .39$ & \\
\hline & $\geq 20$ & $3.64 \pm 0.28$ & & $3.79 \pm 0.42$ & & $3.79 \pm .35$ & \\
\hline \multirow{2}{*}{$\begin{array}{c}\text { Type of } \\
\text { work } \\
\text { shift } \\
\end{array}$} & 3-shift & $3.64 \pm 0.31$ & \multirow{2}{*}{$\begin{array}{c}1.55 \\
(.124)\end{array}$} & $3.67 \pm 0.47$ & \multirow{2}{*}{$\begin{array}{l}-1.54 \\
(.125)\end{array}$} & $3.72 \pm .38$ & \multirow{2}{*}{$\begin{array}{c}.25 \\
(.006)\end{array}$} \\
\hline & Full-time & $3.54 \pm 0.34$ & & $3.81 \pm 0.40$ & & $3.93 \pm .37$ & \\
\hline & $\begin{array}{c}\text { Very } \\
\text { Satisfied }^{\text {a }} \\
\end{array}$ & $3.91 \pm 0.36$ & & $3.99 \pm 0.52$ & & $3.88 \pm .39$ & \\
\hline Satisfa- & Satisfied $^{\text {b }}$ & $3.58 \pm 0.31$ & 5.55 & $3.70 \pm 0.42$ & 4.94 & $3.77 \pm .40$ & 1.62 \\
\hline $\begin{array}{l}\text { ction } \\
\text { with job }\end{array}$ & Mediocre $^{c}$ & $3.62 \pm 0.27$ & $\begin{array}{c}(.001) \\
\mathrm{a}>\mathrm{b}, \mathrm{c}, \mathrm{d}\end{array}$ & $3.64 \pm 0.45$ & $\begin{array}{c}(.003) \\
a, b, c>d\end{array}$ & $3.74 \pm .31$ & 8) \\
\hline & Dissatisfied $^{\mathrm{d}}$ & $3.47 \pm 0.26$ & & $3.21 \pm 0.46$ & & $3.48 \pm .47$ & \\
\hline
\end{tabular}

Table 3. Correlation of nursing competency, role conflict, and nursing professionalism

\begin{tabular}{|c|c|c|c|}
\hline & Empathy $\mathrm{r}(\mathrm{p})$ & Self-efficacy $\mathrm{r}(\mathrm{p})$ & Nursing performance $\mathrm{r}(\mathrm{p})$ \\
\hline Empathy & 1 & & \\
\hline Self-efficacy & $.390^{* *}(<.001)$ & 1 & \\
\hline Nursing performance & $.338^{* *}(<.001)$ & $.617 * *(<.001)$ & 1 \\
\hline
\end{tabular}

\section{Discussion}

In this study, the scores of empathy, self-efficacy, and nursing performance showed various distribution patterns (high or low) in comparison to precedent studies. Although empathy scores were not precisely classified depending on targeted patients, the empathy of 
nurses for the elderly was usually low. According to the results of research by Roh, Kim \& Sok [11], this was probably attributed to nurses' stress from heavy workload with an increasing number of long-stay elderly patients with the rapid increase of the aging population; and elderly patients' inability to actively express their needs due to their cognitive decline including insufficient communication skills. Therefore, it is deemed necessary for nurses who provide the elderly with nursing services to more sensitively respond to their needs, more carefully observe them, effectively manage the job stress stemming from a lack of nursing manpower and heavy workload, and then understand the elderly. Meanwhile, care hospital nurses' self-efficacy scores were similar to those of nurses at general hospitals or clinics but were high compared to those of nurses in integrated nursing care service wards. This suggests that the work environments of care hospitals have been greatly improved compared to the integrated nursing care service wards, which are in the initial stage of implementation. According to Song \& Huh [12], self-efficacy may become low in poor work environments because objective conditions such as work environment affect it. Roh, Kim \& Sok [11] state that self-efficacy is influenced by nursing care time for patients and heavy responsibilities and tasks. This indicates a need for adequate personnel arrangement depending on workload. In the study by Oh \& Wee [13], differences in nursing performance are attributed to working conditions of the relevant medical institution, organizational culture, conditions of inpatients, and nurses' professionalism and proficiency in nursing care. When it comes to the nursing performance scores depending on the medical institution as shown in this study, the scores were found to be not equal even in the same medical institution. In this regard, it is considered necessary to carry out training programs aimed at enhancing professionalism and proficiency in nursing care, which are factors closely related to nursing performance, to improve working conditions and organizational culture, and conduct repetitive follow-up studies on more medical institutions.

Empathy showed a significant difference depending on marital status and satisfaction with nursing as a job. In terms of marital status, the empathy of married nurses was found to be higher than that of single nurses, and this result is to the results of precedent studies [14][15]: married nurses showed greater empathy than single nurses. The reason why satisfaction with nursing as a job influences empathy is that heavy tasks and stress nurses may lead to a lack of emotional empathy and communication between nurses and patients, and personal elements of nurses may also be relevant to empathy. Therefore, nurses' satisfaction with nursing as a job is deemed to be a very important factor in enhancing the empathy of nurses. In addition, self-efficacy showed a significant difference depending on satisfaction with nursing as a job, academic background, and work pattern. Since there are few precedent studies on the relationship between satisfaction with nursing as a job and self-efficacy, precedent studies on job satisfaction, which is regarded as related to satisfaction with nursing as a job, was examined. The study on clinical nurses by Park, Han \& Jo [16] suggests that there is a positive correlation between self-efficacy and job satisfaction of nurses, and lower job stress and higher self-efficacy lead to higher job satisfaction. Their study also states that nurses' self-efficacy is an important factor in increasing job satisfaction [13]. In terms of academic background, self-efficacy was revealed to be higher in nurses who have completed four-year university or graduate school than those graduating from two-year junior college, which is to findings of the study by Han \& Kwon [17] that education level influences self-efficacy. This indicates that the acquisition of new knowledge due to higher education may contribute to increasing professionalism and self-confidence at work, thus enhancing self-efficacy. In terms of work pattern, self-efficacy was higher among fixed-shift nurses than three-shift nurses, which indicates that the fixed shift leads to increased self-confidence at work and further 
enhanced self-efficacy, due to repetition of work through the same work pattern. Based on these study results, it is deemed important to develop programs for establishing work environments and educational programs that help enhance satisfaction with nursing as a job in an attempt to enhance the self-efficacy of care hospital nurses; and to create adequate working conditions at the organizational level. The nursing performance showed a significant difference depending on marital status and work pattern. As for marital status, nursing performance was higher among married nurses than single nurses. This is to the results of the study by Sim \& Kim [18]. The reason why married nurses' nursing performance was higher was probably that they tend to view their current job as stable for their older age and consequently are less likely to consider changing jobs than single nurses, which is considered to give a positive effect on nursing performance. This result is related to married nurses' psychological, social, and emotional stability under the support of their family members despite the burden of combining home and work responsibilities due to marriage and their greater sense of responsibility at work. In addition, with age, their monthly income becomes stable, and their sense of connectedness and attention to their organization increases, which leads to enhanced nursing performance [19]. In terms of work pattern, nursing performance was higher among fixed shift nurses than three shift nurses, and this is also to the results of the study by Lee \& Lee [20].

As for the correlation between empathy and nursing performance, the results of this study are related to those of the study by Lee [21] that emotional intelligence and nursing performance showed a significantly positive correlation. The findings of this study are supported by those of Jeong \& Kim [22] that nurses with greater empathic concern showed greater nursing task performance. As such, nurses with greater empathy are highly likely to appropriately communicate with patients and fellow workers by identifying their emotions or health status when carrying out nursing tasks and to properly resolve conflicts in personal relations. In addition, this study confirmed that there was a positive correlation between empathy and self-efficacy of nurses: the greater the empathy, the higher the self-efficacy. This is related to the findings of Park, Lee \& Kim [14] suggesting the higher the self-efficacy, the higher the empathy, and those of Roh, Kim \& Sok [11] on nursing practice for the elderly, which states that there was a positive correlation between empathy and self-efficacy, and the most influential factor in nursing care for the elderly was empathy.

The self-efficacy of the subjects in this study showed a positive correlation with nursing performance: the higher the self-efficacy, the higher the nursing performance, and this is to the result of the study by Park [23] that higher self-efficacy leads to higher task performance ability, and the influential variable in nurses' task performance ability was self-efficacy. This means that nurses with high self-efficacy are highly likely to be active in performing nursing tasks [20]. Even in the study by Ann [24] conducted on general-duty nurses in general hospitals, the variable with a significant direct effect on nursing performance was selfefficacy. The study by Jung \& Kim [25] on the structural model of nursing performance also revealed that higher self-efficacy led to a greater nursing performance.

\section{Conclusion}

This study was intended to identify correlations between empathy, self-efficacy, and nursing performance among care hospital nurses. When it comes to the relationship between subjects' empathy, self-efficacy, and nursing performance, the nursing performance showed a positive correlation with empathy and self-efficacy. Therefore, it is deemed necessary to develop various empathy programs suited to respective settings for nurses who carry out 
nursing tasks at care hospitals which are in greatest demand in modern society. In addition, it is deemed necessary to create desirable working conditions and actively study and develop training programs for the enhancement of self-efficacy, in an attempt to stimulate nursing performance among care hospital nurses.

\section{References}

[1] M. H. Cho and K. H. Kim, "Perceptions of adequacy and job performance of nurse assistant nursing jobs according to registered nurses and nurse assistants in geriatric hospitals, and caregivers," The Journal of Korean Nursing Administration Academic Society, vol.22, no.4, pp.384- 395, (2016)

[2] Y. S. Hwang and E. Y. Cho, "Factors influencing nurse turnover intention of senior convalescence hospitals in the metropolitan area," Korean Journal of Occupational Health Nursing, vol.25, no.3, pp.156-167, (2016)

[3] J. M. Morse, J. Bottorff, G Anderson, B. O’Brien, and S. Solberg, "Beyond empathy: expanding expressions of caring," J Adv Nurs, vol.53, no.1, pp.75-87, (2006)

[4] J. H. Kim and H. S. Jeong, "Influencing factor on the attitudes toward elders among nurses working at geriatric hospitals: focusing on empathy," The Korea Contents Society, vol.13 no.12, pp.840-850, (2013)

[5] Y. K. Ko and K. H. Kang, "A study on the relationship between self-efficacy, collective-efficacy, and job stress in the nursing staff," J Korean Acad Nurs Admin, vol.12 no.2, pp.276-286, (2006)

[6] W. Duggleby, D. Cooper and K. Penz, Hope, "Self - efficacy, spiritual wellbeing and job satisfaction," Journal of Advanced Nursing, vol.65, no.11, pp.2376-2385, (2009)

[7] S. G. Kim and G. M. Kim, "Nurses' job stress, self-efficacy, and professional self-concept on job satisfaction: a comparison on comprehensive nursing care service wards and general wards," Journal of the Korean Data Analysis Society, vol.20, no.3, pp.1609-1624, (2018)

[8] B. S. Jeon, "The relationship between empathy and altruistic behavior," [Master Thesis], Major in Educational Psychology and Curriculum Department of Education, Graduate School Chungnam National University, Daejon

[9] A. S. Jung, "a study on the relations between a health-promoting behaviors and self-efficacy in general hospital nurse," [Master Thesis], Major in Nursing Administration, The Graduate School of Public Administration Hanyang University, Seoul, (2007)

[10] Y. K. Ko, T. W. Lee, and J. Y. Lim, "Development of a performance measurement scale for hospital nurses," Journal of Korean Academy of Nursing, vol.37, no.3, pp.286-294, (2007)

[11] H. J. Roh, E. J. Kim, and S. H. Sok, "Influences of nurses' empathy and self-efficacy on nursing care of older adults in an Integrated Nursing Care Services (INCS) Unit,” Journal of East-West Nursing Research, vol.25, no.1, pp.9-16, (2019)

[12] J. S. Song and S. Y. Huh, "Moderating effects of self-efficacy and social support on the relationship between resilience and burnout: focusing on nurses' experiences," Health and Social Welfare Review, vol.38, no.4, pp.544-570, (2018)

[13] H. S. Oh and H. Wee, "Self-efficacy, organizational commitment, customer orientation and nursing performance of nurses in local public hospitals," The Journal of Korean Nursing Administration Academic Society, vol.22, no.5, pp.507-517, (2016)

[14] H. J. Park, K. J. Lee, and S. S. Kim, "A comparative study on the counseling self-efficacy and empathy of psychiatric nurses and general ward nurses," Health \& Nursing, vol.26, no.1, pp.9-19, (2014)

[15] E. S. Song, "The factors of empathy for the older patient in general hospital nurses," [Master Thesis], Dept. of Nursing, Graduating School Seoul National University, Seoul, (2015)

[16] E. J. Park, J. Y. Han, and N. Y. Jo, "Effects of professional self-concept, self-efficacy on the job satisfaction in general hospital nurses," Journal of the Korean Data \& Information Science Society, vol.27 no.1 pp.191201, (2016) 
[17] A. L. Han and S. H. Kwon, "Effects of self-leadership and self-efficacy on the nursing performance of nurses working in long-term care hospitals," J Korean Gerontol Nurs, vol.18, no.1, pp.12-21, (2016)

[18] M. R. Sim and K. H. Kim, "Job satisfaction, self-esteem, and nursing task performance among registered nurses and nurse assistants in long-term care hospitals," The Journal of Korean Nursing Administration Academic Society, vol.16, no.4, pp.446-454, (2010)

[19] H. S. Lee, "Influencing factors on the nursing performance of nurses in long-term care hospitals," [Master Thesis], Dept. of Gerontological Nursing, Graduating School Catholic University, Busan, (2015)

[20] S. I. Lee and E. J. Lee, "Effect of nursing work environment," Emotional Labor and Ego-Resilience on Nursing Performance of Clinical Nurses. Korean society for Wellness, vol.11, no.4, pp.267-276, (2016)

[21] H. S. Lee, "Influencing factors on the nursing performance of nurses in long-term care hospitals," [Master Thesis], Dept. of Gerontological Nursing, Graduating School Catholic University, Busan, (2015)

[22] S. J. Jeong and K. H. Kim, "Empathy ability, communication ability, and nursing performance of registered nurses and nursing assistants in long-term care hospitals," The Journal of Korean Nursing Administration Academic Society, vol.23 no.2, pp.249-258, (2017)

[23] E. S. Park, "The relation between self-efficacy and work performance ability of the operation room nurse," [Master Thesis], Dept. of Gerontological Welfare Management, Graduate School of Information in Clinical Nursing Hanyang University, Seoul, (2014)

[24] E. K. Ahn, "A model for clinical nurses' self-efficacy and work performance," [Doctoral thesis], Dept. of Nursing, Graduate School Chungnam National University, Taejon, (2000)

[25] Y. S. Jung and H. S. Kim, "The structural model of nursing performance for advanced beginner-stage nurse," The Korean Journal of Health Service Management, vol.12 no.3, pp.63-78, (2018) 